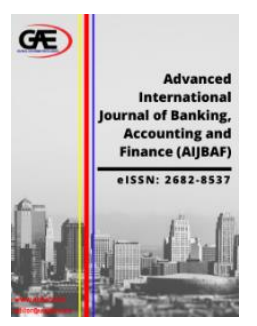

\author{
Advanced International Journal of Banking, \\ Accounting and Finance (AIJBAF) \\ Journal Website: http://aijbaf.com/ \\ eISSN: 2682-8537
}

\title{
DOES FINANCIAL LITERACY REALLY MATTER FOR MALAYSIANS? A REVIEW.
}

\author{
Nor Izzati Mohd Aziz' ${ }^{1}$, Salina Kassim² \\ 1 Institute of Islamic Banking and Finance, IIUM Kuala Lumpur, Malaysia \\ Email: izzati-N@hotmail.com \\ 2 Institute of Islamic Banking and Finance, IIUM Kuala Lumpur, Malaysia \\ Email: ksalina@iium.edu.my
}

\section{Article Info:}

\section{Article history:}

Received date: 05.01 .2020

Revised date: 13.01 .2020

Accepted date: 28.01.2020

Published date: 13.03.2020

\section{To cite this document:}

Aziz, N. I. M., \& Kassim, S. (2020). Does Financial Literacy Really Matter for Malaysians? A Review. International Journal of Banking, Accounting, and Finance, 2 (2), 1320.

DOI: 10.35631/AIJBAF.22002.

\begin{abstract}
:
Malaysians lack financial literacy but are generally unaware of the fact. The national level of financial literacy measured in terms of financial knowledge is still low among Malaysians. A survey by the Credit Counselling and Debt Management Agency (AKPK) found that 1 out of 3 Malaysians rated themselves as having a low level of confidence about financial management. Research on the issue has made some attempt to examine the cause of lower financial literacy and its effects on decision making, but studies have been limited. This paper examines studies on the topic compiled between the years 2017 and 2019 and some surveys made by organizations in Malaysia to see the current scenario of financial literacy in Malaysia. Up to the present, it is clear that current approaches and strategies toward financial literacy have been adhoc. The latest initiative from the Financial Education Network concerned with empowering financial literacy is the National Strategy for Financial Literacy 2019-2023. Each of the organizations involved is committed to improving financial literacy among Malaysian by organizing financial education initiatives such as carnivals, clubs, and seminars. The present study will benefit other researchers and maybe a reference for any organizations that will benefit from the updated statistics and information.
\end{abstract}

\section{Keywords:}

Financial Literacy, Financial Knowledge, Financial Behaviour, Financial Education

\section{Introduction}

People are aware of the importance of improving the level of financial literacy but there is a significant disparity between their self-awareness and actions taken to achieve financial 
literacy. Low financial literacy among the young is one of the factors that contribute to bankruptcies. Malaysians within the age range of 18 to 44 years old face indebtedness, whereas the older generations face the serious financial challenges of retirement. The number of Malaysians declared bankrupt is increasing every year. This may indirectly affect economic growth as the main indicators of economic growth consist of savings, income and investment. The indebtedness problem may also indicate lower levels of savings and investment, which also impacts economic growth.

The AKPK Chief Executive Officer, Azaddin Ngah Tasir emphasized the importance of elevating the level of financial literacy to improve people's financial well-being. Literacy levels affects one's life in terms of financial decision making and financial planning starting from their initial stages of life until retirement. Atkinson and Messy (2012) found that financial literacy is generally higher in terms of financial behavior but financial knowledge is exceptionally low. Higher financial literacy promotes good financial behavior, which in turn, contributes to the growth of a county's economy. Therefore, financial literacy not only benefits individuals, but at a macro level it affects a nation as a whole.

In view of Malaysia's plan to achieve high-income nation status between 2016 and 2020, it was important to see if financial literacy in Malaysia resembles that of developed countries? With a desire to give a better understanding of why bankruptcy is so prevalent among young people, the AKPK (2018) investigated financial behavior (spending, savings and debt management), concluding that at present, Malaysians retain to low level of financial literacy. This was, especially so among the low-income group who tend to have a low level of financial knowledge and prefer to deposit their money rather than investment it because of fear of risk. 1 in 10 Malaysians confessed that they are not disciplined in managing their monthly finances.

\section{Definition of Financial Literacy}

Financial literacy is the measurement of how well an individual can understand and use personal finance-related information. It is divided into two dimensions; understanding/knowledge about personal finances and how to apply personal finances (Huston, 2010). Miller, Godfrey, Levesque \& Stark (2009) agreed that financial literacy can be realized through creating incentives and environments that promote desired financial behaviors, such as saving, budgeting or using credit wisely. Literacy in terms of finance covers consumer credit and over-indebtedness. Of course, both mathematical ability and the understanding of financial terms (Worthington, 2006) combine to benefit the individual in making informed judgments and effective decisions regarding the use and management of money (Huang, Tawfik \& Nagar, 2008).

\section{Literature on Financial Literacy}

\section{Studies in Malaysia}

Although there have been many studies of financial literacy in many different countries, personal finance has received little attention in Malaysia. This is in spite of there being clear reasons literacy is important to raise as an issue in Malaysia today. The present study represents an informed review of the body of literature regarding financial literacy among Malaysians. The findings from those studies were summarized in order to provide an outline of the current financial literacy scenario, as well as to identify the determinants of financial literacy that could be an important part of initiatives to improve financial knowledge, financial behavior and financial attitude. 


\section{Summary, Review and Conclusion of Previous Studies of Financial Literacy (2017 until 2019)}

Hayei \& Khalid (2019). Young generations are likely to be challenged when dealing with financial products because of new advanced technologies, various new age financial products and the complexity in financial transactions. Students from age 15 to 17 years old show impressive results with respect to their level of financial literacy. They have good knowledge of financial costs and returns on investment, even though a lesser number of students are familiar with the basic concept of investment in real estate compared to other assets. This study has found that the element of trust and experience has been of important factors in determining the students' literacy. They tend to imitate their parents' activities, thus the role of parents in shaping their financial behaviour is crucial. Students nowadays have their own culture and attitude, which this study has found to be very important to give serious attention to in order to improve financial literacy. They do not feel the need to track their expenses nor to have a specific monthly budget, and the surplus of daily pocket money was using to having meals or drinks with friends. The borrowing culture is also found to be a current culture among them which is popular among students who do not have enough pocket money, so they are prone to borrowing. Consequently, this attitude fosters a debt attitude. But among the students there are still those who have good savings behaviour where the daily money surplus will be kept in a money box at home, as savings in Tabung haji, and some in bank deposits. This attitude cultivates good savings behaviour for the future. Parents and the school authorities must realize that financial literacy is worth investing time and resources for the future generation, in order to lead financially sustainable lives.

Loh \& Peong (2019). Geographical locations and family characteristics were significantly related to the personal financial literacy of young adults' age 18-35 years who are working in accounting firms, in Malacca. People in rural and urban areas tend to have different levels of financial knowledge. Urban people are more educated and open minded. They were raised according to the family culture and consequently have difference preferences, attitudes and norms. Parents being a role model indirectly teach practices in the form of discussing finances and going shopping with their children. Parenting styles will influence young adults in the way they manage their finances in the future. However, financial education and financial experience do not influence young adults in their financial decision making. In some circumstances financial education may not influence financial literacy, although logically they are related. The school-based education may be insufficient to create awareness on literacy among students as it lacks financial based activities and no seminar or workshop on financial management is organized. The curriculum subjects may also not include financial matters subjects. Financial experience can be obtained from young adults who are used to transactions through the bank account, or who are used to manage monthly educational allowance. They will tend to be more conscious about budgeting and more often become financially savvy. Thus, it is important to encourage young adults to carry less debt, increase their wealth, and have a better financial retirement plan as it has an impact to their lifelong financial well-being

Ashaari \& Md. Yusof (2019). The components of financial literacy which include financial behavior, financial attitude and financial knowledge are important in order to direct working women to have good spending and investing of their funds. This study suggests that working women tend to be financially literate through empowerment in financial education such as having a strategic direction and by conducting seminars. Working women are one of the country's assets who contribute to economic growth. They will contribute in terms of income, 
savings and investment habit whereby the money is being circulated into the economy for better accumulation of assets.

Lee, Arumugam \& Arifin (2019). Young adults have been seen as the future generation, the human resources for the county's growth. Nowadays, credit cards and mortgage loans are easy to secure, and young adults are brought up in a culture of debt which is not good for them in terms of financial planning for future emergency. The level of financial knowledge and literacy will influence personal financial planning. Young working adults' who are aged between 20 to 30 years old are found to generate a positive attitude towards effective financial planning, if they possess higher literacy level. They have to make sufficient investments in their plan and direct those investment plans into suitable vehicles to meet the desired and satisfactory future income objectives and goals. They also may ask financial planners for suggestions in order to build better financial planning.

Mokhtar, Moga Dass, Sabri \& S F Ho (2018). Overall, Malaysians are still lacking in financial knowledge, financial understanding and financial skills which include retirement planning, estate planning and also the awareness towards the roles of financial institutions, i.e. they thought AKPK was offering financial assistance. They are aware of the existence of BNM, Securities Commission, Bursa Saham but do not know in-depth the roles and functions of each financial institutions. Some working people still do not understand the risk and investment:

1. $43.8 \%$ believed they depend on EPF savings to meet living needs after retirement.

2. $83.7 \%$ had expenses higher than income.

3. $62 \%$ believed that debt can be inherited.

Sawandi, Abu Bakar \& Shaari, (2018). The current level of financial literacy among households that are aged between 16 years old and above are still low to moderate. The level has yet to reach a satisfactory standard as to meet financial management skills. The financial literacy level among them is measured through basic financial concepts which include risk, return and inflation. Less than half of them has achieved a high literacy score which is hard for making financial-related decision in future, for savings and retirement plan.

Ab Rahman, Tajudin \& Ahmad Tajuddin (2018). Financial education not only benefits individuals but is also to improve the economic status, as the economy continues to change over the years. Younger generations are considered the economic engines to lead to sustainable development. It is suggested that financial skills and knowledge among them is still low even in advanced countries. In the US, the major problems are the large amount of consumer credit card debt. The study of Islamic financial literacy among students in Malaysia is still low. It is urged to educate them in school or university level so that they can have positive financial management attitudes as a preparation before they enter the job market.

Yong, Yew \& Wee (2018). Young Malaysian working adults residing in the Klang Valley have poor financial management practices which has resulted in them being weak in debt management. Their attitude, which refers to the psychological tendency to decide what is best, being a major role (mediate the effects) in contributing knowledge toward financial behavior. To increase financial knowledge, it is suggested that students and youth be educated through financial education, which gives familiarity to them in terms of the financial products that are available in the market for savings and for future investment.

Ahmad, Mawar \& Ripain (2018). Both financial knowledge and financial education have a different influencing level towards financial literacy. As compared to financial education, 
financial knowledge has more influence on the young generations. Basic knowledge on money and asset management helps to cope with unexpected changes in macroeconomics and high living cost. Meanwhile, financial knowledge through the high value in financial educations will lead to the financial attitude of an individual. The youth who is educated with financial concept and management will be directed to wise financial decision making.

Yong \& Tan (2018). The parent's background plays a major role in the students' financial behavior. Overall, university students present a responsible attitude towards financial management. The majority of university students possess sufficient financial literacy or knowledge, with $72 \%$ of the respondents who have passed the financial literacy components.

Md Nawi, Wan Daud, Ghazali, Yazid \& Shamsuddin (2018). Despite the importance of financial literacy, the Islamic financial literacy is also crucial for the survival of the finance industry, especially Islamic finance. This study proves that a lack of literacy in Islamic finance is actually a serious threat not only to individuals but also for the growth of the Islamic financial industry. This study has proposed four measurement for Islamic financial literacy. These measurements need to strictly adhere to Islamic principles whereby knowledge of the principles (money basics, Islamic banking, Takaful and Shariah-compliant investments) obligates one to behave in accordance to the Shariah.

Ghazali, Azer, Mohamad, Arifin \& Mat (2017). High school students (age between 18 and 19) in Raub, Pahang are not financially literate. They lack awareness of basic finance, even though they already have a bank account for their scholarship purposes. Business students are found to have higher literacy than non-business students. It has been suggested that personal finance subjects are promoted in all schools.

Yew, Yong, Cheong \& Tey (2017). Financial literacy among college and university students in Klang Valley area are low. Financial knowledge is not the only factors that necessarily lead to better financial attitude. Factors that contribute to high literacy also depend on financial socialization factors, i.e. family members and work or life environment. Parents influence the most as they are able to impart relevant knowledge to their children if they are financially literate. Financial education matters by way of conducting the school curriculum in order to give various impacts on financial knowledge and on the attitude of the students.

Abdullah, Ab Wahab, Sabar \& Abu (2017). The factors influencing Islamic financial literacy among university students are to have good attitude towards savings and personal Islamic financial management. It has been found that not more than half of them are literate in the aspects of Islamic investment, credit, financial planning and Takaful.

Antara, Musa \& Hassan (2017). The Small and Medium Enterprise (SMEs), Halal sector has huge potential to contribute into eonomic growth. It is being said, when business owners possess a high level of understanding and literacy of Islamic finance, they will adopt Islamic financing throughout their industry operation, and thus are able to create strong Halal link industry.

\section{Discussion of Current Financial Literacy Issues}

It can be seen from the above studies that the research focus in 2019 was to investigate the determinants of financial literacy among young adults, particularly high school and college students. This was with a view to identifying their literacy level for preparing the students for making better financial decisions in the future. Young adults face huge challenges once they 
start working. The literature suggested that the key factors affecting this younger age group are family and experience. Parental guidance and experience of creating business activities with family or at college level are important.

Several problems were diagnosed among this younger age group, especially students, including their savings and buying habits. A low level of financial knowledge would cause them suffering in the future. University or college students may practice good financial behavior through managing loans or scholarships. Also, at an early age, they might have learned how to accumulate and manage wealth effectively.

This issue among Malaysians youth had, in fact, been identifies years ago, when Prudential Assurance Malaysia Bhd (PAMB) launched an education programs for children in 2011 through the Cha-Ching and Duit Right programs. The aim was to inculcate financial resilience in society. PAMB was eventually recognized as the 'Best Financial Education and Awareness' at Karnival Kewangan 2017 by Bank Negara Malaysia and the Malaysian Financial Industry Institution. The objectives of these programs is to provide a platform to instil money-market skills in children aged between seven and 12. The Duit Right program focused on young people aged between 13 and 15, in the attempt to teach further money management skills.

Most of the literature in 2017 and 2018 focused on working/salaried people to identify their level of financial literacy and to examine how financial education, financial attitude and financial behavior affects them. Working individuals are less likely to manage their consumer credit wisely and lack financial planning. Salaried people have a permanent income that can be separated into savings and expenses. Savings can either be cash-in-hand savings or investments, which are, of course, based on the portion of investment and savings objectives of each individual. Studies show that some people do not have excess money at the end of month to put aside for buying insurance and even to invest in low-risk investments like Unit Trusts. The studies found this is to be due to a lack of knowledge about the financial products available on the financial market.

The rapid growth of Islamic finance should also be mentioned here, as a lack of Islamic financial literacy will not also adversely affect industry growth and is a concern. The focus of financial literacy has, therefore, widened to include Islamic finance industry to promote its growth. The current literature has shown that Malaysians also need to be educated about Islamic product features. To address this need, studies on Islamic financial literacy set up basic measurements to test Islamic literacy, which comprises the concepts of money, Islamic banking, Takaful and Shariah-compliant investment. From here it might be determined whether the level of literacy among Malaysians is either high, medium or low.

\section{New initiatives of the Financial Education Network (FEN): National Strategy for Financial Literacy (2019-2023)}

This 2018 survey updated the current state of financial literacy in Malaysia, in terms of the level of financial knowledge. Low income households tended to have a low level of financial knowledge, with $92 \%$ of individuals having deposit accounts and little take-up of investment products. Regarding saving and budgeting, $84 \%$ of Malaysians claimed to save regularly and do so only for the immediate term, i.e typically withdrawing at the end of the month to cover daily subsistence expenses, As for; readiness for unexpected life events, only $17 \%$ of Malaysians had life insurance or Takaful cover. Regarding planning for retirement, $41 \%$ of Malaysians relied on their EPF savings as their main source of income for retirement. Finally, 
regarding awareness of risk and return, those who were investors were found to have unrealistic expectations.

To address the above scenario, certain initiatives were undertaken:

1. The Ministry of Education, Malaysia - Elements of financial education were to be included in the curriculum for primary and secondary school students, adapting materials from subjects like moral education, accounting, business, and economics.

2. Bank Negara Malaysia - Karnival Kewangan, Train-the-Trainers program was inducted among counselors in government agencies in order to give them guidance on how to conduct educational programs.

3. Employees Provident Fund - The Retirement Advisory Service (RAS) aimed to raise financial literacy in order to improve the level of retirement savings and to help better retirement plans.

\section{Conclusion}

Financial literacy has affected more than just households. Studies has been conducted in Malaysia to test all age groups from students (Ibrahim et al.; 2010), Fazli \& MacDonald; 2010) \& Albeerdy \& Gharleghi; 2015), to salaried/working adults (Boon et al.; 2011), Idris, et al; 2013) \& Ali et al.; 2014). A high focus has been on students because of the financial challenges they will face on entering working life, in terms of managing a salary. Studies showed that, even though this group were not yet working, they actually still had valuable learning experiences from managing pocket money given by their parents, and from managing educational loans and scholarships.

Overall, it can be concluded from past studies that, Malaysians of all ages and backgrounds still possessed a low level of financial literacy. Most Malaysians only understood that one's income must always be able to cover expenses, without knowing that other financial products like insurance were also important to cover unforeseen circumstances. There was generally also a lack of savings.

\section{Suggestions}

Overall, all involved organizations are urged to give priority to financial literacy to all levels of the Malaysian community. Continuous financial education must be provided to all students. Improvements in financial attitudes and behavior may also be realized through financial socialization tools such as financial planners, media, the internet, and schools/universities. The most important influencer is, of course, parents as the first source of financial, guidance as studies have shown clear effects of early intervention.

\section{Directions for Future Research}

In discussing several directions for future research, studies of Islamic financial literacy are certainly needed. The study should also focus more on low income workers in Malaysia as they usually face accumulated debts because of high living costs. Studies might also review the effectiveness of the programs conducted by other institutions. Literacy might also be tested among genders to identify any differences, as it is assumed that females prefer bank deposits to investments. If so, targeting females might help them to obtain better information on financial products, such as investment schemes and attributes.

\section{References}

Abdullah, M. A., Ab Wahab, S. N. A., Sabar, S. \& Abu, F. (2017). Factors determine Islamic Financial Literacy among Undergraduates. Journal of Emerging Economies and Islamic Research, 5(2), 67-76. 
Ali, P., Anderson, M., McRae, C., \& Ramsay, I. (2014). The financial literacy of young Australians: An empirical study and implications for consumer protection and ASIC's National Financial Literacy Strategy. Company and Securities Law Journal, 32, 334352.

Antara, P. M., Musa, R. \& Hassan, F. (2017). Conceptualization and Operationalization of Islamic Financial literacy Scale. Pertanika Journal Social Sciences and Humanities, 25(S), 251-260.

Ashaari, N. N., \& Yusof, Z. B. (2019). Relationship between Financial Literacy and Its Component: A Research on Working Women. Asian Journal of Probability and Statistics, 5(2), 1-6.

Atkinson, A. \& Messy, F. (2012). Measuring Financial Literacy: Results of the OECD, International Network on Financial Education (INFE) Pilot Study, OECD Working Papers on Finance, Insurance and Private Pensions, No. 15, OECD Publishing.

Ghazali, M. S., Azer, I., Mohamad, S. A., Arifin, N. A. M. \& Mat, A. (2017). Personal Financial Literacy among High School Students in Raub Pahang Malaysia. Journal of Engineering and Applied Sciences, 12(9), 2280-2284.

Hayei, A. A., \& Khalid, H. (2019). Inculcating Financial Literacy among Young Adults through Trust and Experience. International Journal of Accounting, Finance and Business, 4(18), 78-91.

Lee, D., Arumugam, D. \& Arifin, N. (2019). A Study of Factors Influencing Personal Financial Planning among Young Working Adults in Kuala Lumpur, Malaysia. International Journal of Recent Technology and Engineering 7(5), 114-119.

Loh, A. M. \& Peong, K. K. (2019). Determinants of Personal Financial Literacy among Young Adults in Malaysian Accounting Firms. Global Journal Business Social Science Review, 7(1), 8-19.

Nawi, F. A. M., Daud, W. M. N. W., Ghazali, P. L., Yazid, A. S. \& Shamsuddin, Z. (2018). Islamic Financial Literacy: A Conceptualization and Proposed Measurement.

International Journal of Academic Research in Business and Social Sciences, 8(12), 629-641.

Mokhtar, N, Moga Dass, T., Sabri, M. F. \& S F Ho, C. (2018). A Preliminary Evaluation of Financial Literacy in Malaysia. Journal of Wealth Management and Financial Planning, 5(6), 3-16.

Sawandi, N., Abu Bakar, A. S., Shaari, H., Saad, R. A. \& Amran, N. A. (2018). Financial Literacy among Malaysian: Level of Financial Knowledge Score. The Journal of Social Science Research, 6, 300-304.

Yong, C. C., Yew, S. Y. \& Wee, C. K. (2018). Financial Knowledge, Attitude and Behavior of Young Working Adults in Malaysia. Institutions and Economies, 10(4), 21-48.

Yong, H. A. \& Tan, K. (2018). The influence of Financial Literacy towards Risk Tolerance. International Journal of Business and Society, 18(3), 469-484.

Yew, S. Y., Yong, C. C., Cheong, K. C. \& Tey, N. P. (2017). Does Financial Education Matter? Education Literacy among Undergraduates in Malaysia. Institutions and Economies, 9(1), 43-60. 